\title{
Kinetics of graphitization of thin diamond-like carbon (DLC) films catalyzed by transition metal
}

\author{
N. Boubiche ${ }^{\mathrm{a}, \mathrm{b}}$, J. El Hamouchi ${ }^{\mathrm{a}}$, J. Hulik ${ }^{\mathrm{a}}$, M. Abdesslam ${ }^{\mathrm{a}, \mathrm{c}}$, C. Speisser ${ }^{\mathrm{a}}$, F. Djeffal ${ }^{\mathrm{d}}$, \\ F. Le Normand ${ }^{\mathrm{a}, *}$ \\ ${ }^{a}$ MaCEPV/ICube, Université de Strasbourg and CNRS, 23 rue de Loess, BP 20CR, 67037 Strasbourg, France \\ ${ }^{\mathrm{b}}$ Department of Physics, University of BATNA-1, 05000 Batna, Algeria \\ ${ }^{\mathrm{c}}$ Department of Radiation Physics, University of Science and Technology Houari Boumediene, Alger, Algeria \\ ${ }^{\mathrm{d}}$ Department of Electronics, University of BATNA-2, 05000 Batna, ALGERIA
}

\section{A R T I C L E I N F O}

\section{Keywords:}

Diamond-like carbon

Thin graphite films

Metal catalyst

Pulsed laser deposition

Thermal treatment

Raman spectroscopy

Optical transmission and absorption

Electric transport measurements

\begin{abstract}
A B S T R A C T
In this paper, we have studied the kinetics of graphitization at $773 \mathrm{~K}$ of thin diamond-like carbon (DLC) films coated with minute amount of Ni metallic particles. DLC films are deposited at room temperature by pulsed laser deposition (PLD) on a transparent quartz substrate, and Ni is deposited on the surface of DLC using molecular beam epitaxy technique at room temperature. The ultra-high vacuum thermal (range 573-873 K with $60 \mathrm{~min}$ annealing treatments) and kinetic (range $30-3760 \mathrm{~min}$ at $773 \mathrm{~K}$ ) behaviors of the deposited films are investigated. Surface and interface characterizations indicate that the growth of graphitic $\mathrm{sp}^{2}$ clusters starts at temperatures lower than $573 \mathrm{~K}$. The kinetics of graphitization is recorded at $773 \mathrm{~K}$. Thus, the continuous growth of graphitic clusters leads to a long-range kinetics. These clusters are responsible for the increase in the electrical conductivity and carrier mobility, reaching values of $6.10^{3}$ Siemens $/ \mathrm{cm}$ and $20 \mathrm{~V} / \mathrm{cm}^{2} \times \mathrm{s}$, respectively. This continuous change is not only explained by the nucleation and growth of graphitic clusters, but also by some reorientation of them alongside both the surface and the quartz substrate. The obtained results demonstrate that thermally post-treated catalytic metal/DLC films are promising materials for conductive electrodes and sensing applications.

Prime novelty and projected interest

Kinetics of graphitization at $773 \mathrm{~K}$ of thin diamond-like carbon (DLC) films coated with minute amount of Ni metallic particles;

High surface electrical conductivities, which are quite promising and competitive in comparison to literature data dealing with transparent electrodes.

Correlation between conductivity models and Raman measurements in Catalytic Metal/DLC material.
\end{abstract}

\section{Introduction}

Graphene is a 2D planar material of hexagonal structure comparable to a honeycomb network [1]. This unique structure infers outstanding properties like very large electrical [2] and thermal [3] conductivities, a high planar Young modulus combined with a high flexibility [4] and optical transparency [5]. In addition, ultra-thin graphitic films (UTGF) exhibit properties close to those of the graphene monolayer, at least with graphitic layers less than 5 monolayers [6]. However, applications of UTGF as transparent electrodes require new elaboration technique with large size, low-temperature and thickness control. Moreover, it is also recommended to grow UTGF films directly on an appropriate substrate to avoid any transfer step. To reach these objectives at a moderate cost, the growth of UTGF by chemical vapor deposition (CVD) and related processes using metallic catalyst appears promising technique. However, the elaborated graphene films using this technique contain undesirable impurities like hydrogen and impose other transfer steps, which can degrade the graphene performance [7]. Another solution to avoid the transfer step is the formation of graphitic layers from diamond-like carbon (DLC) films grown by pulsed laser deposition (PLD) at room temperature as well as by other PVD processes, followed by post-treatments. Under appropriate conditions, a tetrahedral amorphous carbon (ta-C) film is formed by PLD. These ta-C films exhibit many properties close to those of diamond, due to a high but tunable

\footnotetext{
* Corresponding author.

E-mail address: francois.le-normand@unistra.fr (F. Le Normand).
} 
concentration of $\mathrm{sp}^{3}$-hybridized carbon [8]. Moreover, they initially exhibit a $\mathrm{sp}^{2}$-enriched surface $[9,10]$, that can be totally graphitized by subsequent thermal [11-14] or laser [15] treatments. A double process has been described in the literature including: 1) the clusterization into graphitic cycles of $\mathrm{sp}^{2}$ single or olefinic chain sites initially embedded in a large network of $\mathrm{sp}^{3}$ carbon at rather low temperatures (low activation energy) and 2) the direct transformation of $\mathrm{sp}^{3}$ carbon to $\mathrm{sp}^{2}$ carbon at higher temperatures (high activation energy). These posttreatments not only infer a drastic stress reduction, but also the films exhibit low surface conductivity. A derived elaboration process includes the incorporation of a catalytic transition metal like Ni, Pt... during or after the DLC deposition. It is presumed these metallic nanoparticles would act as catalytic centers accelerating the graphitization at lower temperatures. This effect has been early described in the literature with a conductivity variation of several orders of magnitude, but this result has thereafter no more received much attention [16]. The catalytic effect would indeed affect the graphitization process both on kinetic and thermodynamic viewpoints to elaborate high quality films, without structural or chemical modifications [14]. To the best of our knowledge, few studies have investigated the kinetics of graphitization of thin diamond-like carbon (DLC) films at a given temperature [17]. In this perspective, in this paper we report both thermal and kinetic studies of the graphitization of $\mathrm{Ni} / \mathrm{ta}-\mathrm{C} /$ quartz films to elaborate few graphitic layers on top of the ta-C film. Raman investigations, optical transmission and conductivity measurements have been carried out to determine the optical and electrical properties of the elaborated films for eventual applications as transparent electrodes, biosensors and electrochemical cells $[18,19]$.

\section{Materials and methods}

Samples were prepared by a triple step process. First carbon was deposited on quartz (double-face polished) by PLD at room temperature with a vacuum base higher than $10^{-3} \mathrm{~Pa}$. A KrF laser source $(248 \mathrm{~nm}$ wavelength, $30 \mathrm{~ns}$ pulse frequency) was used with a nuclear-grade graphite target (purity $5 \mathrm{~N}$ ) at a substrate-target distance of $5 \mathrm{~cm}$. The laser fluence was within the range $4-6 \mathrm{~J} / \mathrm{cm}^{2}$, which corresponds to approximately $2 \times 10^{8} \mathrm{~W} / \mathrm{cm}^{2}$, a power density for which we found a maximum of $\mathrm{sp}^{3}$ carbon formation [20]. The deposited ta-C film thickness was around $15 \mathrm{~nm}$. Further experimental details on the preparation, the determination of the $\mathrm{sp}^{3} / \mathrm{sp}^{2}$ ratio and the carbon density of the films are reported in references $[20,21]$. Samples studied here have a density of about $3 \mathrm{~g} / \mathrm{cm}^{3}$ and $70 \%$ of $\mathrm{sp}^{3}$ content.

$\mathrm{Ni}$ metal is subsequently deposited at room temperature by molecular beam epitaxy (MBE) on DLC/quartz samples at a minute amount of metal (around $0.15 \mathrm{~nm}$ of equivalent metal layer). The thickness of evaporated Ni was measured by Rutherford back scattering (RBS) as described in [22]. This is typically a deposition of less than one equivalent metallic monolayer, carried out 1 ) to avoid single layer formation and thus direct metallic surface conductivity and 2) to optimize the catalytic properties of small nanoparticles.

The samples $\mathrm{Ni} / \mathrm{ta}-\mathrm{C} /$ quartz were finally subjected to thermo-catalytic treatments in ultra-high vacuum (UHV) furnace (base pressure $10^{-4} \mathrm{~Pa}$ ). The samples were taken out of the UHV chamber after each treatment. Then new measurements (Raman spectroscopy, UV-vis transmission, conductivity) were carried out before a new thermo-catalytic treatment was implemented. The samples Ni-DLC-3 samples were treated from $573 \mathrm{~K}$ up to $873 \mathrm{~K}$ by steps of $100 \mathrm{~K}$ (Table 1 ). After setting the samples into the UHV furnace, a heating rate of $10 \mathrm{~K} / \mathrm{min}$ was applied up to the desired temperatures. After treatment was achieved, samples were cooled down in UHV without instructions. Samples NiDLC- 1 and Ni-DLC- 2 were similarly treated at $773 \mathrm{~K}$ from a first treatment of $30 \mathrm{~min}$ up to a cumulative time of $3765 \mathrm{~min}$ with variable increasing time sequence. Besides, a reference sample (DLC-4), similar to Ni-DLC-3 sample but without catalyst was investigated at $773 \mathrm{~K}$ for $60 \mathrm{~min}$. Table 1 summarizes the properties of the samples used in this
Table 1

Main characteristics of the $\mathrm{Ni} / \mathrm{DLC} /$ quartz samples.

\begin{tabular}{llllll}
\hline Sample & $\begin{array}{l}\text { Laser } \\
\text { fluence } \\
\left(\mathrm{J} / \mathrm{cm}^{2}\right)\end{array}$ & $\begin{array}{l}\text { DLC } \\
\text { thickness } \\
(\mathrm{nm})\end{array}$ & $\begin{array}{l}\text { Ni thickness } \\
(\mathrm{nm})\end{array}$ & $\begin{array}{l}\text { Annealing } \\
\text { time }(\mathrm{min}) \text { at } \\
773 \mathrm{~K}\end{array}$ & $\begin{array}{l}\text { Annealing } \\
\text { temperature T } \\
\text { at 60 min }\end{array}$ \\
\hline Ni-DLC-1 & 5 & 16 & 0.16 & $30-3765$ & 773 \\
Ni-DLC-2 & 5 & 13 & 0.13 & $30-3765$ & 773 \\
Ni-DLC-3 & 4.1 & 9.5 & 0.13 & 60 & $573-873 \mathrm{~K}$ \\
DLC-4 & 5.6 & 9.5 & - & 60 & 873 \\
\hline
\end{tabular}

work. Sample Ni-DLC-1 and Ni-DLC-2 exhibit similar characteristics, except the thickness values, which are slightly different. As it has been reported that the microstructure of ta-C films changes along the axis normal to the surface [23], it is expected that the thickness could be a significant parameter in affecting the film performance. In addition, we check by ERDA that the samples are free from hydrogen impurities.

SEM images were obtained on a Zeiss GeminiSEM 500 working at $3 \mathrm{keV}$ with secondary electrons emission and total yield detection modes, to contrast the topographic from the chemical information. Atomic force microscopy (AFM) on a NT-MDT Stand Alone SMENA setup is used in the resonant semicontact mode. Raman spectroscopy and mapping measurements have been carried out using a LabRam/Aramis/ Jobin-Yvon spectrometer with the green laser at $532 \mathrm{~nm}$. The light was filtered to get a laser power of $1.5 \mathrm{~mW}$ on the sample to avoid damages in the carbon layer, using a $50 \mu \mathrm{m}$ hole (confocal configuration), a monochromator of 2400 lines/mm and a magnitude lens of 100 . Raman spectra were recorded in the $300-3000 \mathrm{~cm}^{-1}$ range. For Raman mapping, a set of $20 \times 20$ spectra distant each other by $0.5 \mu \mathrm{m}$ was recorded. The spectra were then treated by removing the background and normalizing the signal to the intensity of the G signal. For some films, the light was focused either on the surface or at the interface with quartz. In the last case, the sample was turned with the light crossing the transparent quartz down to the interface. This was possible as the quartz samples were also polished on bottom face (RMS in the range $0.5-1.0 \mathrm{~nm}$ ). Moreover, we tuned the intensity ratio of the $\mathrm{G}$ line with the Si line at $520 \mathrm{~cm}^{-1}$ to check the accuracy of the focalization. The conductivity measurements were performed using Hall effect technique (ECOPIA HMS-5000 set up) in the Van der Pauw configuration. Electric conductivity, in the planar orientation, as well as the nature, the mobility and the density of the carriers were determined. Knowing the thickness $\mathrm{t}(\mathrm{cm})$ of the conductive layer, the conductivity $\sigma(\mathrm{S} / \mathrm{cm})$ of the film can be expressed as:

$\sigma=\mathrm{w} /\left(\mathrm{t} \times \mathrm{L} \times \mathrm{R}_{\mathrm{s}}\right)$

where $\mathrm{w}$ and $\mathrm{L}$ are the width and the length of the sample, respectively, and $R_{S}(\Omega / \square)$ denotes the sheet resistance.

The optical transmission of the films has been measured using a NIR Perkin ELMER spectrophotometer Lambda 19. The spectra were recorded from 250 to $850 \mathrm{~nm}$, using a sweep rate of $120 \mathrm{~nm} / \mathrm{min}$. The slit width was fixed to $2 \mathrm{~nm}$. Moreover, the recorded spectra were analyzed according to the approach described in [24], derived from Tauc's analysis, which can separately determine the nature of the optical transition and deduce the optical band gap $\mathrm{E}_{\mathrm{g}}$.

\section{Results}

\section{A) Structural characterization}

A SEM image of the Ni-DLC-1 sample after 3765 min of cumulative thermocatalytic treatment at $773 \mathrm{~K}$ is displayed at two magnitudes in Fig. 1A and B, respectively. The low magnitude spectrum shows a large and homogeneous spread of particles on the substrate. However, images recorded with a higher magnitude reveal that these spots are split into many single nanoparticles with a mean size of about $20-30 \mathrm{~nm}$. This splitting can be the result of a possible carburization of the Ni particles. 
A
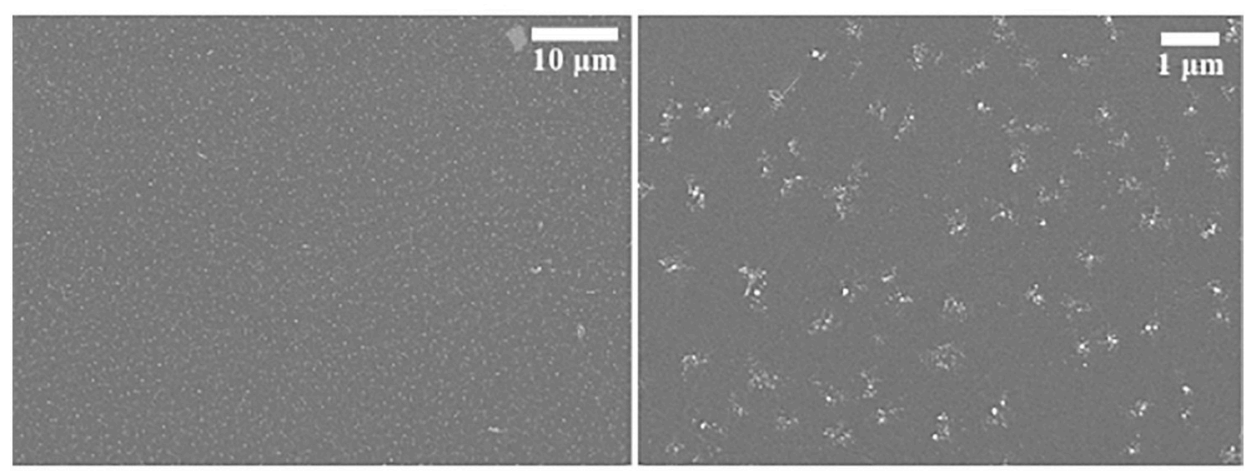

C

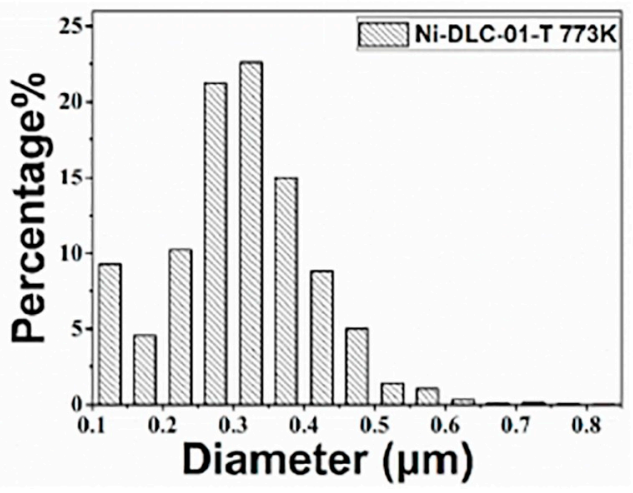

D

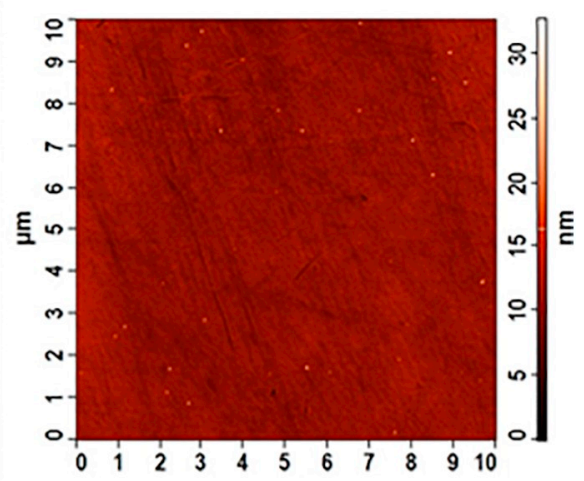

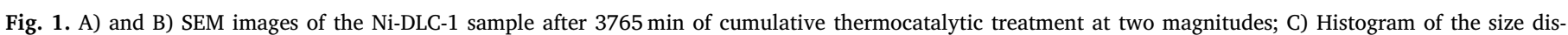
tribution of set of nanoparticles displayed in Fig. 1A on more than 2500 nanoparticles using ImageJ software; D) AFM image of sample DLC-1 (without nickel).

$\mathrm{Ni}$ in the presence of carbon can form a carbide phase $\mathrm{Ni}_{3} \mathrm{C}$ which is thermodynamically stable within the temperature range 473-673 K [25]. The decomposition of unstable $\mathrm{Ni}_{3} \mathrm{C}$ particles above $673 \mathrm{~K}$ might lead to such configuration for the nanoparticles. The Ni nature of the nanoparticles is validated by energy-dispersive X-ray spectroscopy. The size distribution of the set of nanoparticles displayed in Fig. 1C and obtained over 2500 particles over a surface area of $208 \mu \mathrm{m}^{2}$ is randomly distributed with a maximum around $0.3 \mu \mathrm{m}$ (Fig. 1C). The surface roughness was measured from AFM to $0.6 \mathrm{~nm}$ on sample DLC-1 (without nickel) (Fig. 1D).

\section{B) B) Temperature treatment by Raman spectroscopy}

We first investigated by Raman spectroscopy the effect of UHV thermal post-treatments. The sequence of Raman spectra (Ni-DLC-3 sample) are plotted on the surface and at the interface, respectively, as initially prepared and then after subsequent thermocatalytic treatments from 573 to $873 \mathrm{~K}$ (Fig. 2A and B). From these figures, a broad complex band within the $1100-1650 \mathrm{~cm}^{-1}$ range characteristic of carbon contributions is recorded. These Raman spectra are roughly similar with previous reports on ta-C films prepared by PLD using the same nanosecond $\mathrm{KrF}$ source [9], or under similar conditions [26]. This broad band points out a D band centered around $1360 \mathrm{~cm}^{-1}$ and a G band centered at $1560-1590 \mathrm{~cm}^{-1}$. The intense $\mathrm{G}$ band is due to the stretching $6 \mathrm{E} 2 \mathrm{~g}$ mode of $\mathrm{sp}^{2}$-hybridized carbon, whatever the nature (single, chain, cycle, ...) of $\mathrm{sp}^{2}$ carbon sites. By contrast, the $\mathrm{D}$ band is due to a multiphotonic process of $\mathrm{sp}^{2}$ carbons and involves defects like edge sites of graphitic cycles. Thus, the ratio $\mathrm{I}_{\mathrm{D}} / \mathrm{I}_{\mathrm{G}}$ of the intensities of these bands is a measurement of the cyclisation of the $\mathrm{sp}^{2}$ carbon of nanometer size when starting from a highly defective carbon material like ta-C prepared at room temperature [27]. A careful analysis at the initial spectra focused on the surface shows that a D contribution is initially present at a low concentration. Thus, very small graphitic-like fragments are formed in the initial DLC structure. Nevertheless, it should be highlighted that the DLC structure consists in a $\mathrm{sp}^{3}$-rich carbon network surrounding small $\mathrm{sp}^{2}$-rich carbon fragments [8]. Therefore, other very weak contributions arise at around $1060 \mathrm{~cm}^{-1}$ (T mode), $1190 \mathrm{~cm}^{-1}\left(\nu_{1}\right)$ and $1480 \mathrm{~cm}^{-1}\left(\nu_{3}\right)$ carbon vibration modes at the interface between the graphitic clusters in growth or in formation and the carbon $\mathrm{sp}^{3}$ network. The two latter lines are characteristic of disordered $\mathrm{sp}^{3}$ hybridization state of carbon $[8,28]$, like $\mathrm{sp}^{3}$-hybridized carbons in close vicinity of the $\mathrm{sp}^{2}$ clusters. It is generally reported that the Raman ratio between $\mathrm{sp}^{3}$ and $\mathrm{sp}^{2}$ carbon is very weak [29], but in our case with a laser source at $2.33 \mathrm{eV}$ and band gap around $1 \mathrm{eV}$, we may have some $\mathrm{sp}^{3}$ carbon vibration modes.

Finally, the attribution of the $\mathrm{T}$ mode at $1060 \mathrm{~cm}^{-1}$ is more discussed, as being due either to carbyne chains or to diamond nanocrystalline form [28]. Besides, these lines are much more intense on the spectra recorded at the interface, which means that a higher level of $\mathrm{sp}^{3}$ carbon is formed at the interface (Fig. 2B). This suggests a gradient of $\mathrm{sp}^{2} / \mathrm{sp}^{3}$ carbon across the film, in agreement with the subplantation model of carbon DLC film growth [30-32]. By contrast the assignment of these lines to some $\mathrm{Si}-\mathrm{C}$ bonds can be excluded [33].

Notable changes occur after successive thermocatalytic treatments from 573 to $873 \mathrm{~K}$. The intensity of the D band increases, the position of the $\mathrm{G}$ band shifts towards higher wavenumbers, from $1570 \mathrm{~cm}^{-1}$ to $1575-1580 \mathrm{~cm}^{-1}$, and a narrowing of both D and G (from $170 \mathrm{~cm}^{-1}$ to $130 \mathrm{~cm}^{-1}$ ) bands occurs. By comparison, the ratio $\mathrm{I}_{\mathrm{D}} / \mathrm{I}_{\mathrm{G}}$ is around 0.6 on the sample DLC-4 (without Ni) instead of 0.75 on the sample NiDLC-3 after $60 \mathrm{~min}$ at $873 \mathrm{~K}$ (Fig. 2-C). This is an indication of the catalytic effect of the Ni particle for $\mathrm{sp}^{2}$ carbon cyclization. These two effects are explained by the process of cyclization of carbon $\mathrm{sp}^{2}$ 
$\boldsymbol{A}$

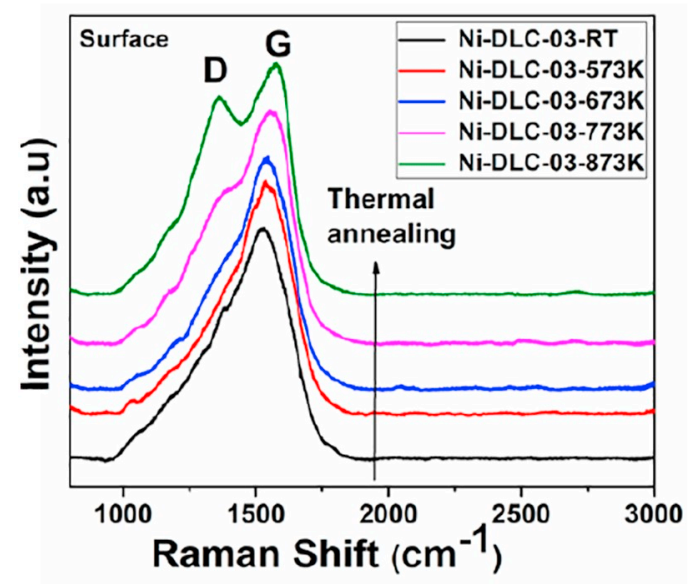

$B$

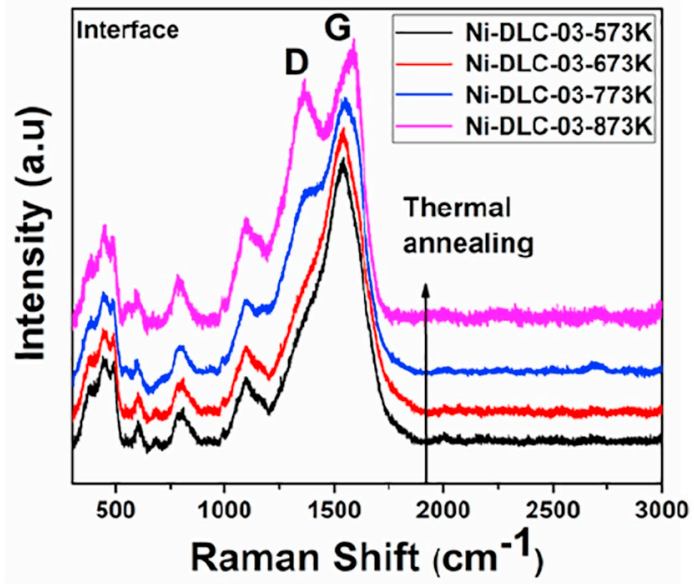

C

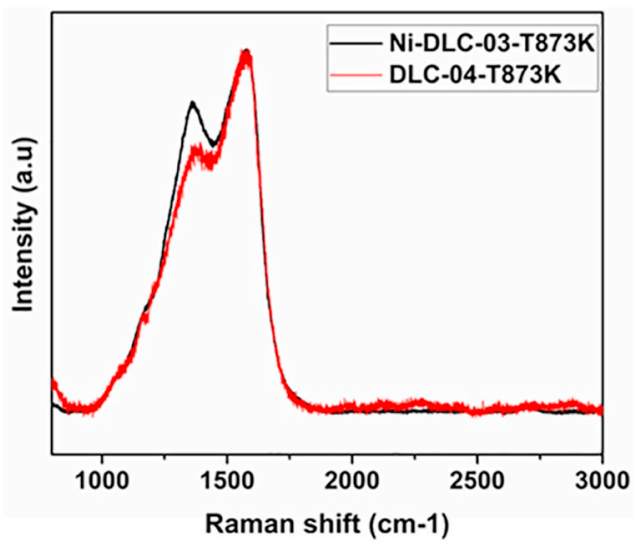

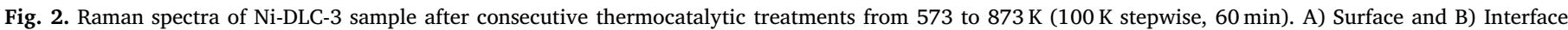

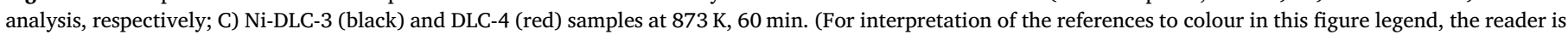
referred to the web version of this article.)

fragments aggregating carbon $\mathrm{sp}^{2}$ sites. Also, the arising at high temperature $(T=873 \mathrm{~K})$ of a weak $2 \mathrm{D}$ band at around $2700 \mathrm{~cm}^{-1}$ can be noticed (Fig. $2 \mathrm{~A}$ ). This $2 \mathrm{D}$ band is a multiphotonic process, and its occurrence can be considered as a signature of some weak organization of the graphitic fragments in the direction normal to the planar graphene plane. In contrast, $\mathrm{sp}^{3}$ carbon bands do not change in intensity and remains weak. This is an indication that the carbon $\mathrm{sp}^{3}$ to $\mathrm{sp}^{2}$ transformation does not occur at these temperatures [8]. The lower wavenumber lines at around 500 and $800 \mathrm{~cm}^{-1}$ are due to $\mathrm{Si}-\mathrm{O}$ and $\mathrm{Si}-\mathrm{Si}$ vibrations, respectively, and do not evaluate in intensity.

However, it is important to note that the DL films are not in an equilibrium state, and thus evolution of the carbon structure process is not only temperature-dependent, but also may be time-dependent. This is why we performed a comprehensive kinetics study at a given temperature equals to $773 \mathrm{~K}$.

C) Kinetics of graphitization

1) Raman spectroscopy

The sequences of Raman spectra, recorded at both the surface and at the interface, are displayed as a function of the cumulative time of thermocatalytic treatment (from 30 to $3765 \mathrm{~min}$ ) in Fig. 3A and B, respectively. From these figures, we observe a progressive increase of the $\mathrm{D}$ line compared to the $\mathrm{G}$ line. At the interface, we note also some weak but significant carbon $\mathrm{sp}^{3}$ and $\mathrm{T}$ bands (with some dispersion of the intensities due to the error in the focalization at the interface), whereas the $\mathrm{D}$ and $\mathrm{G}$ bands characteristics of $\mathrm{sp}^{2}$ carbon remains unchanged. We have calculated the ratio of intensities (surface areas) $\mathrm{I}_{\mathrm{D}} / \mathrm{I}_{\mathrm{G}}$ according to a process analysis that has been described in more details in literature [21] and which is summarized here. The whole Raman lines in the range $1000-1650 \mathrm{~cm}^{-1}$ is fitted with five Gaussian-shape contributions which are the G, D, $\nu 3, \nu_{1}$ and $T$ lines around $1560-1590 \mathrm{~cm}^{-1}$, $1360 \mathrm{~cm}^{-1}, 1470-1495 \mathrm{~cm}^{-1}, 1180 \mathrm{~cm}^{-1}$ and $1060 \mathrm{~cm}^{-1}$, respectively. The baseline was first subtracted from Raman spectra before starting the analysis. Fig. 3 is an example of deconvolution of the Raman spectrum of the sample DLC-4 (773 K-60 min). This analysis provides important information about each peak (Full Width at Half Maximum (FWHM) and wavenumber $\left(\mathrm{cm}^{-1}\right)$, area and peak intensities). The intensity ratio of the two peaks $D$ and $G$ is used to evaluate the crystallite size of the $\mathrm{sp}^{2}$-hybridized graphitic domains [27]. The surface $I_{D} / I_{G}$ curves are plotted in Fig. 3D for the Ni-DLC-1 and Ni-DLC-2 samples. For both samples Ni-DLC-1 and Ni-DLC-2, this ratio starts with a slow raise, and then the increase becomes more pronounced above $200-300 \mathrm{~min}$. The saturation apparently does not occur, even after near $4000 \mathrm{~min}$ of thermal treatment. As these samples have rather similar characteristics, both curves give a good indication of the experimental dispersion of the results.

If we consider that the variations of the $\mathrm{D}$ band are mainly due to 
$\boldsymbol{A}$

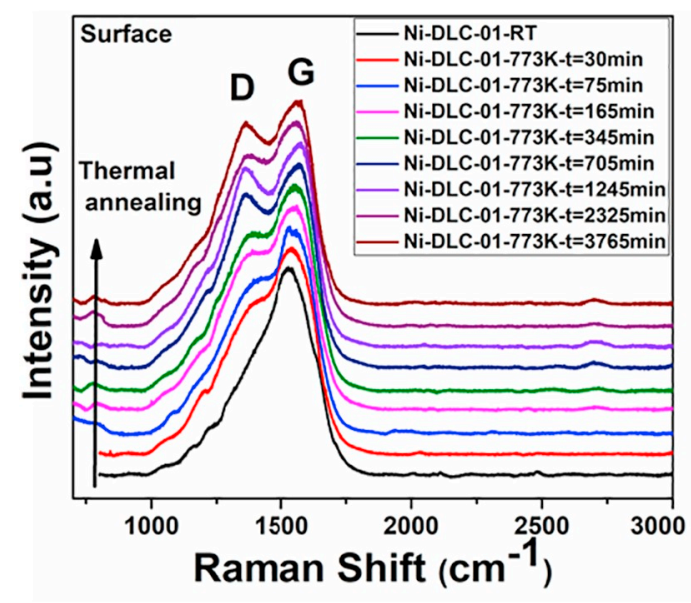

C

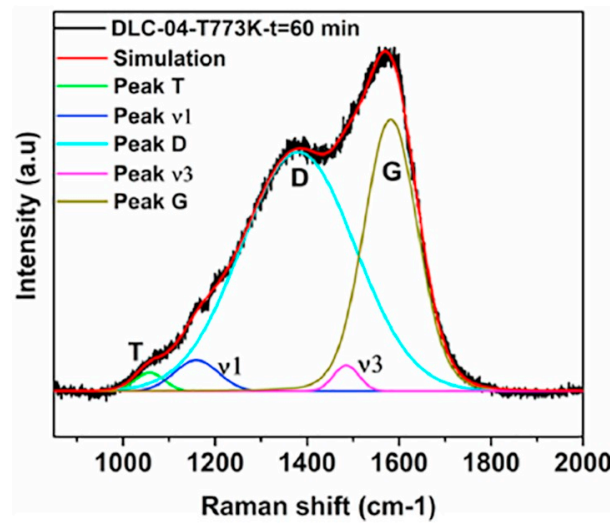

$B$

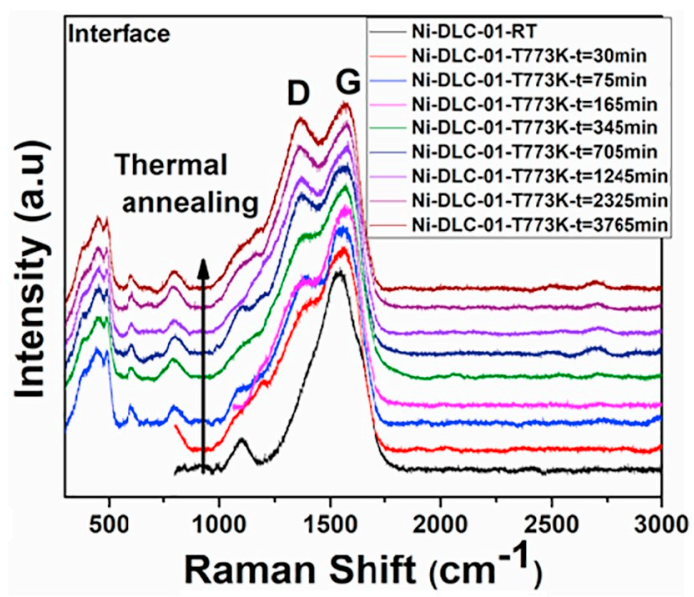

D

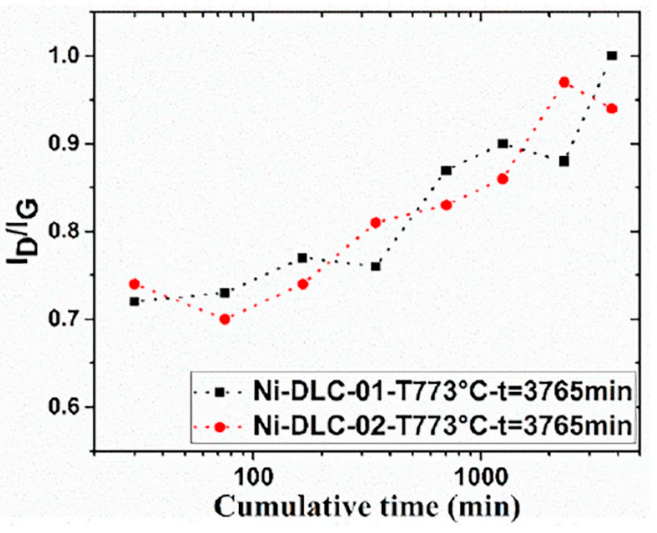

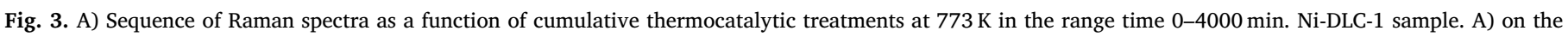

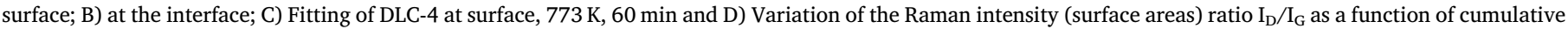
thermocatalytic treatment at $773 \mathrm{~K}$ on Ni-DLC-1 and Ni-DLC-2 samples.

the nucleation and growth of graphitic cycles, the increase of the $\mathrm{I}_{\mathrm{D}} / \mathrm{I}_{\mathrm{G}}$ ratio is an indication of the formation and growth of graphitic cycles in the course of the thermocatalytic treatments. This formation of graphitic cycles clearly takes a long time before completing stabilization and is not even achieved at $773 \mathrm{~K}$ after $4000 \mathrm{~min}$ of cumulative thermal treatments. Meanwhile, the $\mathrm{G}$ band remains stable around $1575 \mathrm{~cm}^{-1}$ and the FWHM of the G band decreases from $164 \mathrm{~cm}^{-1}$ to $137 \mathrm{~cm}^{-1}$. It is expected however that the process involves not only the formation and growth of graphitic rings, but also ordering of the graphitic cycles and a reorientation of them in a direction parallel to the surface [28]. The occurrence of a weak $2 \mathrm{D}$ band at $2700 \mathrm{~cm}^{-1}$ above around $700 \mathrm{~min}$ of cumulative treatment, even if it remains invariably low, is an indication of a starting ordering of the graphitic layers.

\section{2) Raman mapping}

The Fig. 4A and B display the Raman surface mapping of the normalized intensities ratio $\mathrm{I}_{\mathrm{D}} / \mathrm{I}_{\mathrm{G}}$ and $\mathrm{I}_{2 \mathrm{D}} / \mathrm{I}_{\mathrm{G}}$, respectively, obtained on the sample Ni-DLC-1 after thermocatalytic treatment of $3765 \mathrm{~min}$ at $773 \mathrm{~K}$, associated with the optical image on the same area (Fig. 4C). The Fig. 4D displays the $I_{D} / I_{G}$ image after $180 \mathrm{~min}$ at $773 \mathrm{~K}$. The two $\mathrm{I}_{\mathrm{D}} / \mathrm{I}_{\mathrm{G}}$ images (Fig. 4A and D) are displayed with the same colour amplitude of 0.3 (0.5-0.8 and 0.9-1.2 range, with mean values 0.65 and 0.95 , respectively, in agreement with the $\mathrm{I}_{\mathrm{D}} / \mathrm{I}_{\mathrm{G}}$ intensities reported in Fig. 3D of 0.75 and 0.95 at $180 \mathrm{~min}$ and $3765 \mathrm{~min}$, respectively). Clearly, the last image displays bright areas contrasted with darker zones. The limited resolution of the camera however precludes to assign these areas to catalytic particles which are in the nanometer scale. The size of the catalytic domains (Fig. 1B) is however of the same order of magnitude than the bright spots delivered by the optical image in Fig. 4C. Therefore, it is tempting to assign the small dark red domains with high $\mathrm{I}_{\mathrm{D}} / \mathrm{I}_{\mathrm{G}}$ ratio values (1.15-1.20 in the intensity scale of Fig. 4A) to the Ni large domains observed in Fig. 1. These areas can be assigned to preferential graphitic areas. In contrast, the areas with the lower $\mathrm{I}_{\mathrm{D}} / \mathrm{I}_{\mathrm{G}}$ ratio values are considered as carbon $\mathrm{sp}^{3}$-enriched domains. The mapping at 180 min exhibits much less contrast indicating that between 180 and 3765 min both nucleation and growth of domains with high $\mathrm{I}_{\mathrm{D}} / \mathrm{I}_{\mathrm{G}}$ occur. Reversely, we fail to find a matching between the $\left(\mathrm{I}_{2 \mathrm{D}} / \mathrm{I}_{\mathrm{G}}\right)$ and the $\left(\mathrm{I}_{\mathrm{D}} /\right.$ $\mathrm{I}_{\mathrm{G}}$ ) mappings (Fig. 4A and $\mathrm{B}$, respectively), or a matching between the $\left(\mathrm{I}_{2 \mathrm{D}} / \mathrm{I}_{\mathrm{G}}\right.$ ) mapping and the optical image (Fig. $4 \mathrm{~B}$ and $\mathrm{C}$, respectively). The reason may be due to the very weak intensity of the $2 \mathrm{D}$ line, even after a long treatment at $773 \mathrm{~K}$. Moreover, it is likely that local conditions like roughness, orientation of the $\mathrm{sp}^{2}$ cycles are more important at this level.

\section{3) UV-vis transmission}

The Fig. 5A plots some optical transmission curves of the Ni-DLC-1 sample with successive thermocatalytic post-treatments at $773 \mathrm{~K}$ in the UV-visible range $250-800 \mathrm{~nm}$. The transmission of the quartz alone remains constant, at around $93 \%$. In this figure, it is clearly shown the transmittance is decreased to $65 \%$ at $550 \mathrm{~nm}$ for Ni-DLC- 1 sample. The influence of the metal deposition on the transmission spectrum of the untreated sample (not shown) is negligible. After a first treatment, at 
$\mathbf{A}$

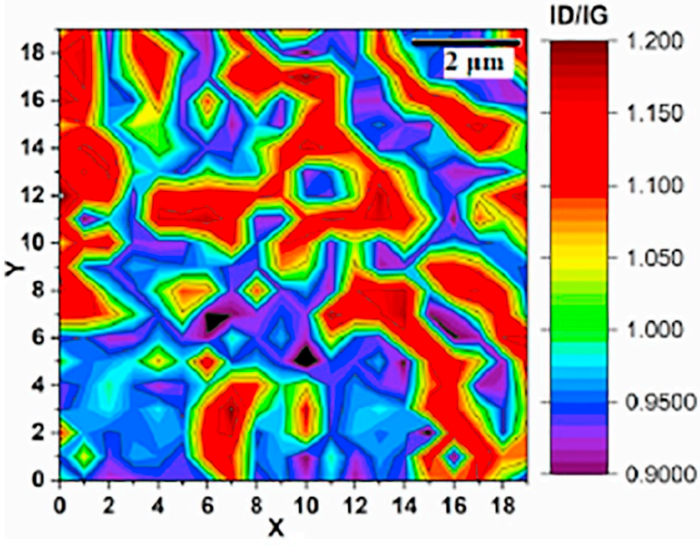

C

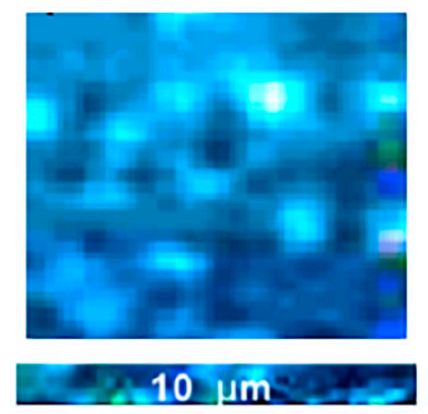

B

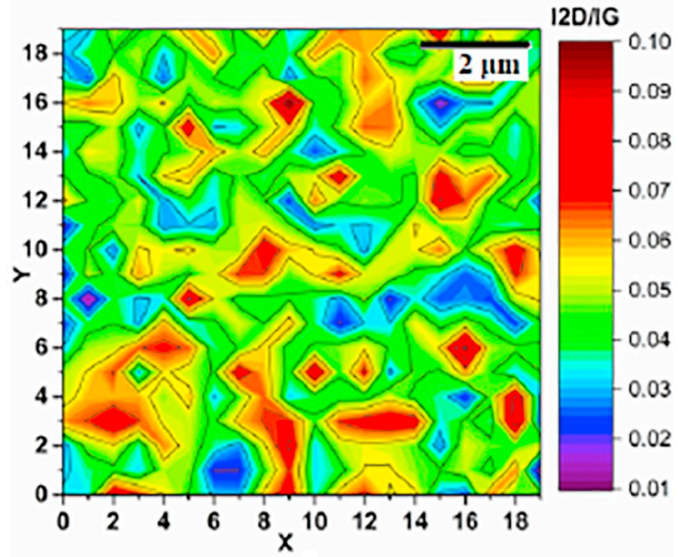

D

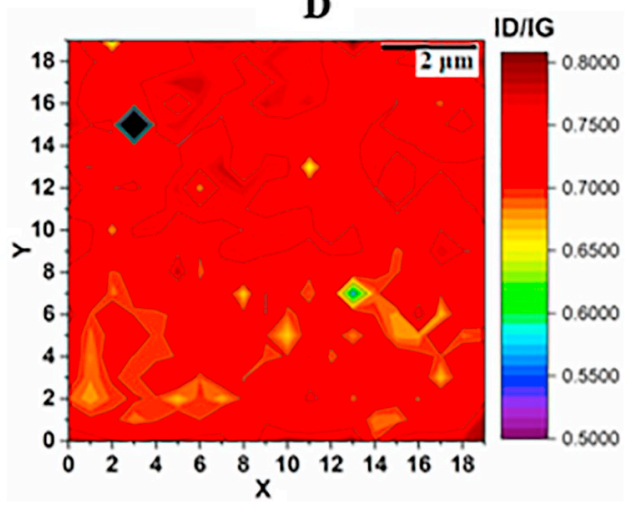

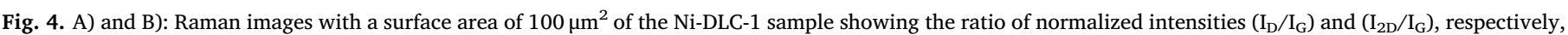

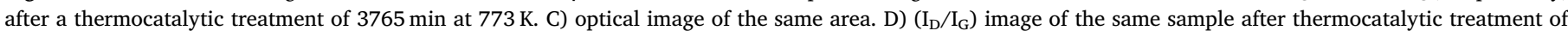
$180 \mathrm{~min}$ at $773 \mathrm{~K}$ with the same colour amplitude than in Fig. 4A (different area).

$773 \mathrm{~K}$ for $30 \mathrm{~min}$, the transmittance is slightly decreased to $55 \%$ at $550 \mathrm{~nm}$. Then, some saturation is attended after approximately $1000 \mathrm{~min}$ (Fig. 5C in which the transmissions at $550 \mathrm{~nm}$ are corrected for the quartz absorption). These results are in good agreement with the progressive formation of graphitic aromatic clusters. However, a close inspection in the near-UV range reveals some slight changes in the transmittance behavior. Fig. 5D plots the variation of optical band gap $E_{g}$ as function of time extracted according to [24]. $E_{g}$ is initially measured on DLC-01 and DLC-02 samples at $1.1 \mathrm{eV}$. It drops to $0.95 \mathrm{eV}$ with deposition of nickel. Starting the thermal treatment at $773 \mathrm{~K}$, it drops again to slightly less than $0.8 \mathrm{eV}$. It is shown in Fig. $5 \mathrm{D}$ that the optical band gap increases first with time to reach a maximum value of $0.85-0.88 \mathrm{eV}$ for an annealing time equals to $60 \mathrm{~min}$. After $60 \mathrm{~min}$, the optical band gap is decreased to near $0.6-0.65 \mathrm{eV}$ with some trend to saturation. This signifies that the cumulative annealing time has a significant impact on the DLC film electrical behavior.

We finally compare the samples Ni-DLC-3 and DLC- 4 (without Ni) of same thickness and both treated $60 \mathrm{~min}$ at $873 \mathrm{~K}$ (Fig. 5B). The sample DLC- 4 exhibits a transmission of around $90 \%$ at $550 \mathrm{~nm}$, much higher than the transmission on Ni-DLC-3 sample around $65 \%$. This is a clear evidence of the catalytic behavior of $\mathrm{Ni}$ which accelerates the formation of aromatic domains, highly absorbing the light.

\section{4) Transport measurements}

We have first checked that the untreated Ni-DLC-01 and Ni-DLC-02 samples exhibit no conductivity within the detection limits (less than $10^{-3} \mathrm{~S} / \mathrm{cm}$ ).

Fig. 6A illustrates the variation of the electrical conductivity, $\sigma$, versus the cumulative annealing time. From this figure, it is clearly shown that the samples Ni-DLC-1 and Ni-DLC-2 exhibit high conductivity values in the $10^{3}-10^{4} \mathrm{~S} / \mathrm{cm}$ range. The conductivity behavior shows three power regimes in a logarithmic scale. The first one, up to $200 \mathrm{~min}$, displays a small increase with a linear slope of 0.32 , the second one occurs in the range $200-1500 \mathrm{~min}$ with a steeper increase (linear slope of 0.7) and finally a saturation or even a slight decrease is observed above $1000 \mathrm{~min}$. The overall increase is larger than one order of magnitude (Fig. 6A), from initially around $8.10^{2} \mathrm{~S} / \mathrm{cm}$ to $7.10^{3} \mathrm{~S} / \mathrm{cm}$ after $1245 \mathrm{~min}$ of cumulative thermocatalytic treatment. The two samples yield very similar conductivities, except for the third regime. The main conclusion is that the transport conductivity of Ni-DLC samples is never stabilized at an annealing temperature of $773 \mathrm{~K}$ over a large range time.

We compared the conductivities of Ni-DLC-3 and DLC-4 samples treated under the same conditions $(873 \mathrm{~K}, 30 \mathrm{~min})$. We find $1.910^{3} \mathrm{~S}$ / $\mathrm{cm}$ for the metal-loaded sample and we do not observe any conductivity on the unloaded sample. The catalytic effect of the metal on conductivity is clearly observed.

The mobilities of the carriers are reported in Fig. 6B for Ni-DLC-2 sample. The Hall effect measurements indicate that conductivity of thin layers graphite was both due to positive (holes) and negative charge carriers (electrons). This affects the determination of the Hall constant of the carrier mobility and of the carrier concentration.

The Hall constant $R_{H}$ is then expressed as

$\mathrm{R}_{\mathrm{H}}=(1 / \mathrm{e}) \times\left(\mathrm{p}-\mathrm{n} \times \mathrm{b}^{2}\right) /(\mathrm{p}+(\mathrm{n} \times \mathrm{b}))^{2}$

where $\mathrm{p}$ and $\mathrm{n}$ are the positive and negative carrier concentrations, respectively, and $b=\mu_{\mathrm{e}} / \mu_{\mathrm{h}}$ is the ratio of the mobility values. The total 
A

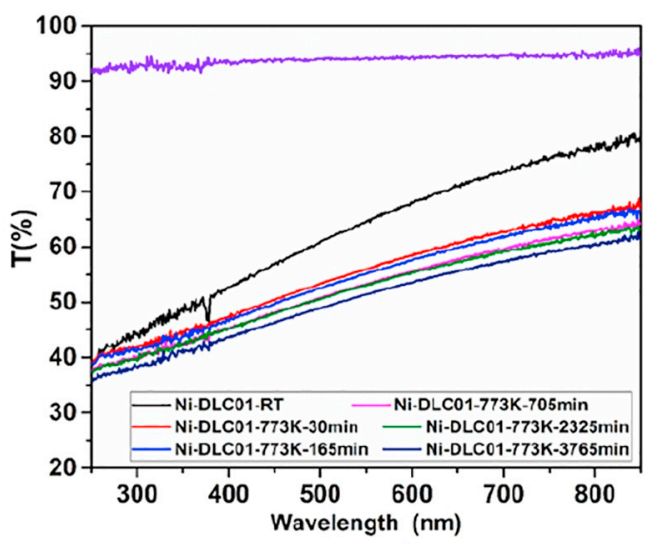

C

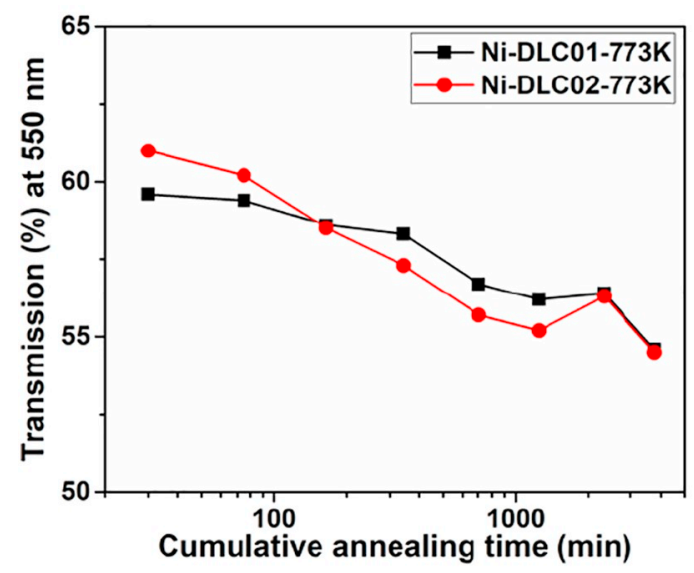

B

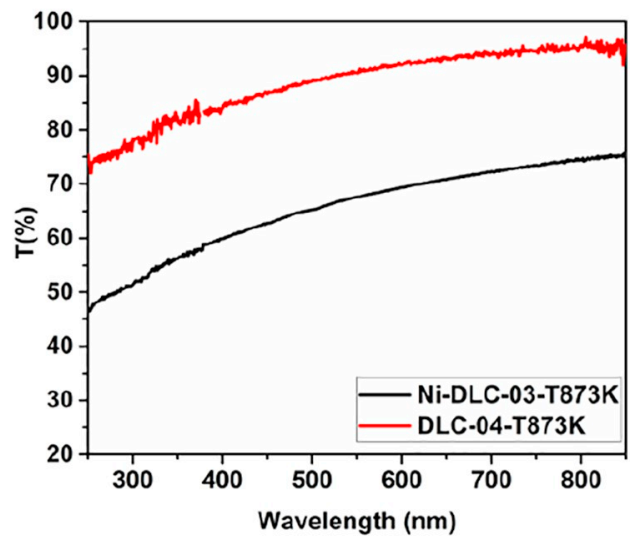

D

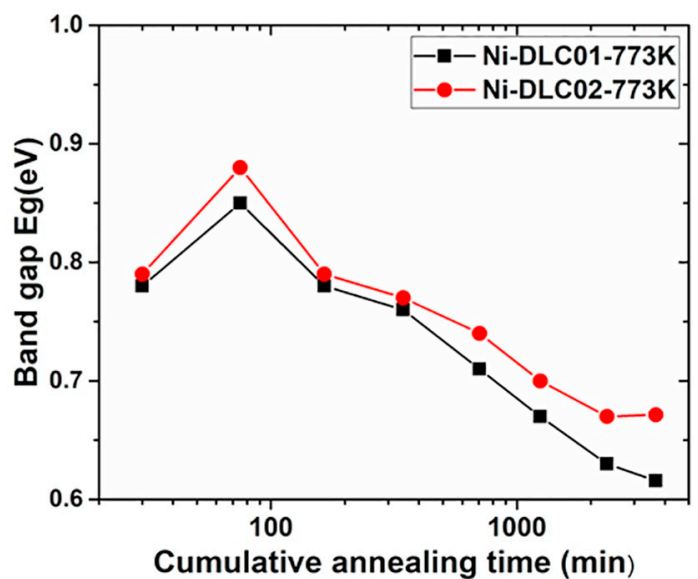

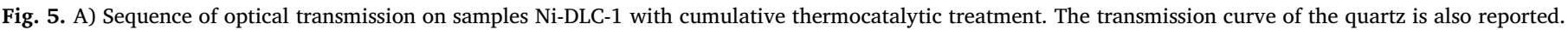

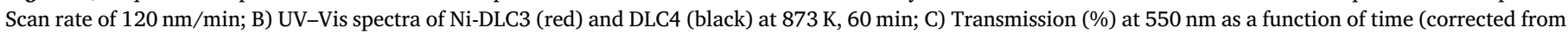

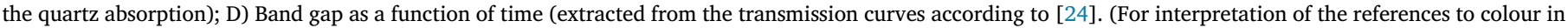
this figure legend, the reader is referred to the web version of this article.)

A

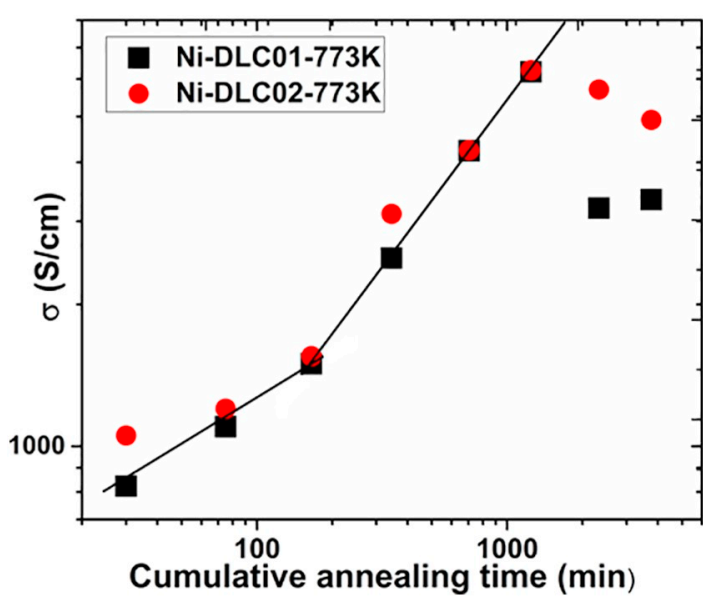

B

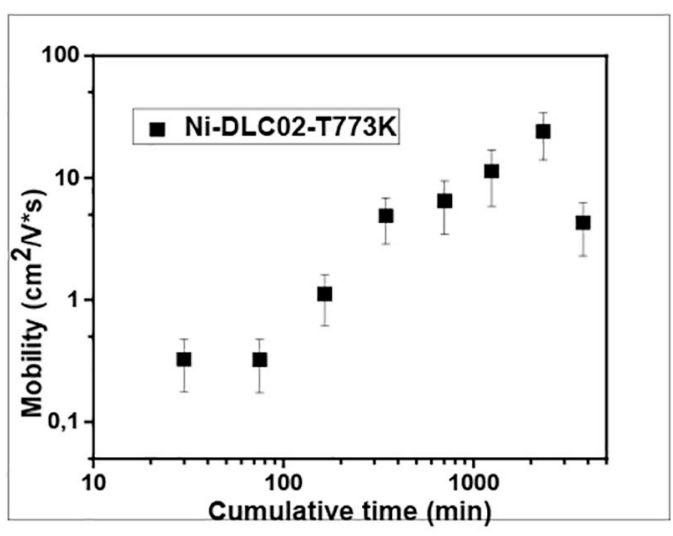

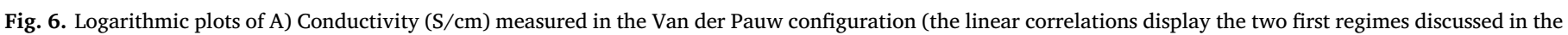
text); B) Carrier mobility as a function of the cumulative annealing time (Ni-DLC-2 sample).

density of charge carriers $\mathrm{n}+\mathrm{p}$ can then be expressed as:

$\mathrm{n}+\mathrm{p}=(1+\mathrm{R}) \times\left(1-\mathrm{R} \times \mathrm{b}^{2}\right) / \mathrm{e} \times \mathrm{R}_{\mathrm{H}} \times(1+\mathrm{R} \times \mathrm{b})^{2}$

The electron and hole mobilities $\mu_{\mathrm{e}}$ and $\mu_{\mathrm{h}}$, respectively, defined as $\sigma=\left(\mu_{\mathrm{e}} \times \mathrm{e} \times \mathrm{n}+\mu_{\mathrm{h}} \times \mathrm{e} \times \mathrm{p}\right)$, can be expressed as:

$\mu_{\mathrm{e}}=\mathrm{R}_{\mathrm{H}} \times \mathrm{b} \times \sigma /\left(1-\mathrm{R} \times \mathrm{b}^{2}\right)$

and 


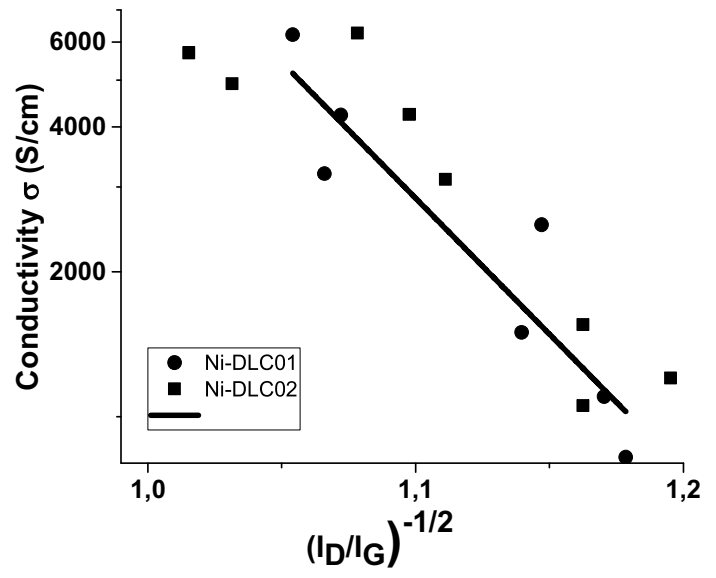

Fig. 7. Correlation between the conductivity variation and the Raman $I_{D} / I_{G}$ ratio according to the Eq. (10).

$\mu_{\mathrm{h}}=\mu_{\mathrm{e}} / \mathrm{b}=\mathrm{R}_{\mathrm{H}} \times \sigma /\left(1-\mathrm{R} \times \mathrm{b}^{2}\right)$

where $\mathrm{R}=\mathrm{n} / \mathrm{p}$ is the ratio of charge densities. Neglecting again the contribution of impurities, we take this ratio as $R=1.33$ obtained on pyrolytic graphite [34]. To support this assumption, it has been checked by a statistical analysis (more than 100 independent Hall measurements) that the ratio of major $\mathrm{n}$ type over $\mathrm{p}$ type conductivity is 1.24 .

Fig. 6B reveals that the electron mobility increases with time to reach a maximum mobility value of $20 \mathrm{~cm}^{2} /(\mathrm{V} \times \mathrm{s})$ for a time of thermocatalytic treatment equals to $2000 \mathrm{~min}$. The carrier density given by Eq. (3) is quoted to around $10^{20}-10^{21} \mathrm{~cm}^{-3}$. It must be noted that the transport properties obtained, with mobility of around $20 \mathrm{~cm}^{2} /$ V.s at the best, are quite comparable with a recent publication on ta-C:H samples annealed at higher temperatures [35].

\section{Discussion}

It is worthy to mention that the kinetics of surface conductivity is rather complex and its interpretation needs further investigation. However, it is possible to rely such behavior with the Raman analysis.

The relation between the conductivity and the nanostructure has been often studied in ta-C films, but only the thermal effect has been investigated on ta-C $[17,36,37]$ and ta-C-H films [38]. Two processes occur that contributes in improving the conductivity with time or temperature: 1 ) clustering of the $\mathrm{sp}^{2}$ phase into $\mathrm{sp}^{2}$ cyclic domains and 2) carbon $\mathrm{sp}^{3}$ to carbon $\mathrm{sp}^{2}$ conversion. However, owing to high activation energy we can rule out this last process that occurs only at high temperatures. Moreover, the $\mathrm{sp}^{2}$ cluster orientation is also important in the surface conductivity, with an optimum configuration for surface conductivity when the cluster domains are oriented parallel to the surface. At room temperature, transport in ta-C films can be described by hopping between near neighbor $\mathrm{sp}^{2}$ clusters and the conductivity $\sigma$. The latter is expressed as [36,37]:

$\left.\sigma=\mathrm{K} \times\left(\mathrm{d}^{2} / \mathrm{T}\right) \times \exp \cdot\{-[\mathrm{E} /(\mathrm{k} \times \mathrm{T})]-(2 \times \mathrm{d}) / \mathrm{a}]\right\}$

where $a$ is the localization radius of the conducting states, $d$ is the distance between the near neighbor $\mathrm{sp}^{2}$ clusters, $\mathrm{E}$ expresses the activation energy of the transport process and $\mathrm{K}$ is a constant. Assuming a random and homogeneous distribution of graphitic spherical clusters, the localization radius $a$ can be assigned to the cluster radius. The hopping distance $d$ can be expressed as $d=D-2 a$, where $D$ is the mean distance between two near-neighbor $\mathrm{sp}^{2}$ clusters. Then $\mathrm{D}$ can be expressed as a function of the cluster density $\mathrm{N}$ as $\mathrm{D}=\mathrm{k} / \mathrm{N}^{1 / 2}$, where $\mathrm{N}$ represents the cluster density and $\mathrm{k}$ is a geometric parameter. Thus, the hopping distance $d$ can be expressed as a function of the cluster density $\mathrm{N}$ and the cluster mean size as: $\mathrm{d}=\left(\mathrm{k} / \mathrm{N}^{1 / 2}\right)-2 \mathrm{a}$

at a fixed temperature and from expressions (6) and (7), the conductivity can be given by:

$\sigma=\mathrm{K}^{\prime}(\mathrm{T}) \times\left[\left(\mathrm{k} / \mathrm{N}^{1 / 2}\right)-2 \mathrm{a}\right]^{2} \times \exp .\left\{-\left[2 \times \mathrm{k} /\left(\mathrm{a} \times \mathrm{N}^{1 / 2}\right)\right]\right.$

where $\mathrm{K}^{\prime}(\mathrm{T})$ is a constant that involves all the temperature-dependent parameters. In the absence of any more data about the independent time variations of the localization radius $\mathrm{a}(\mathrm{t})$ and the cluster density $\mathrm{N}$ (t), it is difficult to go further in the analysis without supplementary assumptions. However, the localization radius is correlated to the cluster size $\mathrm{L}_{\mathrm{a}}$ in a hopping transport model as:

$\mathrm{a}=\mathrm{C} \times L_{a} /\left[\mathrm{E}_{\pi}\left(\mathrm{L}_{\mathrm{a}}\right)-\mathrm{E}_{\sigma}\right]^{1 / 2}$

where $E_{\pi}\left(L_{a}\right)$ and $E_{\sigma}$ are the electronic gaps between $\pi-\pi^{*}$ and $\sigma-\sigma^{*}$ states, respectively. $E_{\pi}\left(L_{a}\right)$ is strictly depending on the cluster size as reported by Robertson [39]. For large clusters however, like here as ascertained by large Raman $\mathrm{I}_{\mathrm{D}} / \mathrm{I}_{\mathrm{G}}$ ratio, $\mathrm{E}_{\pi}\left(\mathrm{L}_{\mathrm{a}}\right)$ is constant, so $\mathrm{a} \approx \mathrm{C}_{1} \times \mathrm{L}_{\mathrm{a}}$ with $\mathrm{C}_{1}=\mathrm{C} /\left[\mathrm{E}_{\pi}-\mathrm{E}_{\mathrm{\sigma}}\right]^{1 / 2}$. In the phase of graphitic clusters growth with increasing $\mathrm{I}_{\mathrm{D}} / \mathrm{I}_{\mathrm{G}}, \mathrm{I}_{\mathrm{D}} / \mathrm{I}_{\mathrm{G}} \propto \mathrm{L}_{\mathrm{a}}{ }^{2}$ [27]. Moreover, we can assume that the density $\mathrm{N}(\mathrm{t})$ is rapidly constant as the metal particle acts as a nucleation center for graphitic clusters, then $N(t) \approx N_{0}$. Then equation $\{8\}$ reduces to:

$\operatorname{Ln} \sigma=\mathrm{C}(\mathrm{T})-\left(\mathrm{D} /\left(\mathrm{I}_{\mathrm{D}} / \mathrm{I}_{\mathrm{G}}\right)^{1 / 2}\right)$

A plot of Ln $\sigma=$ versus $\left(\mathrm{I}_{\mathrm{D}} / \mathrm{I}_{\mathrm{G}}\right)^{-1 / 2}$ is displayed in Fig. 7 for both samples Ni-DLC-1 and Ni-DLC 2 samples. It shows a reasonable agreement with a negative linear slope of $-1 / 2$, considering the error on $I_{D} /$ $\mathrm{I}_{\mathrm{G}}$.

Another explanation can be found in close insight on the variations of the Raman ratio $I_{D} / I_{G}$ with time. This ratio is expected to be dependent on both the density and on the size of the cluster radius, and clearly supports the increase of the conductivity with time. Moreover, the power laws with time distinguish two regimes. We propose that the first regime is a nucleation kinetics domain, where the conductivity is mainly governed by the variations of $\mathrm{N}^{1 / 2}$, whereas the second regime is a growth kinetics regime which is mainly governed by the variations of the mean size $a$. This could be related to the slope ratio between the first and the second regime around $0.32 / 0.7 \approx 0.46$, not far from $1 / 2$ as expected from Eq. (8). Moreover, the improvement of the conductivity at a given temperature may be also the result of a reorientation of the $\mathrm{sp}^{2}$ clusters from the normal direction to the surface to an orientation parallel to the substrate. In the PLD process under our conditions it is believed that carbon ions impinge the surface with kinetic energy around $100 \mathrm{eV}$ or more. Within these kinetic energies $\mathrm{sp}^{2}$ carbon may be formed with a preferential orientation along the pathway of carbon ions inside the ta-C film, thus rather perpendicular to the surface. This has been shown for example for the formation of graphitic clusters normal to the surface during the diamond nucleation assisted by carbon ion bombardment [40]. It is expected that the graphitic clusters will tend to reorient themselves with time or temperature in the direction parallel to the surface or the interface with substrate to minimize the biaxial stress of the graphitic cluster sheets.

Therefore, the improvement of the conductivity at a given temperature may be also the result of a reorientation of the $\mathrm{sp}^{2}$ clusters from a direction normal to the surface to an orientation parallel to the substrate. This is supported by the literature report where conductivities were recorded in both directions, perpendicular and parallel to the surface as a function of thermal treatment. A cross is clearly observed between two measurements [37]. This process is expected to be a slow process as it involves the movement of the carbon atoms of the graphitic cluster. Finally, the last regime is a saturation/degradation of the conductivity. It is proposed that in this regime the density and/or the size of the graphitic clusters become so high that their coalescence starts. 


\section{Conclusions}

In this work, we have studied the kinetics of graphitization at $773 \mathrm{~K}$ of thin diamond-like carbon (DLC) films coated with Ni metallic nanoparticles. DLC films are deposited at room temperature by pulse laser deposition (PLD) on a transparent quartz substrate. Moreover, a Ni metal (less than one equivalent monolayer) is deposited on the surface of DLC using molecular beam epitaxy technique at room temperature in order to create $\mathrm{Ni}$ nanoparticles. Ultra-high vacuum annealing treatments (range $573-873 \mathrm{~K}$ with $60 \mathrm{~min}$ ) show a transformation of carbon $\mathrm{sp}^{2}$ single or chain sites into cyclic aromatic domains which is probed by the Raman $\mathrm{I}_{\mathrm{D}} / \mathrm{I}_{\mathrm{G}}$ ratio. Studied for the first time to our knowledge, a comprehensive kinetic study of thermocatalytic treatments on Ni-DLC samples in the range $30-3760 \mathrm{~min}$ at $773 \mathrm{~K}$ shows a continuous process of $\mathrm{sp}^{2}$ clusters formation and growth using Raman spectroscopy, optical transmission and electrical conductivity measurements. The kinetic behavior is analyzed in terms of nucleation and growth of graphitic $\mathrm{sp}^{2}$ clusters, probably encompassed by a long-range kinetics of reorientation of the graphene layers of the graphitic clusters moving from normal to parallel direction to the surface and the interface. A correlation is found between the Raman $\mathrm{I}_{\mathrm{D}} / \mathrm{I}_{\mathrm{G}}$ ratio and the conductivity in agreement with the nucleation and growth of graphitic clusters. Further studies are however required to monitor independently the kinetic of graphitic cluster formation, growth, orientation and coalescence. High surface electrical conductivities are reached accordingly, at more than $6 \times 10^{3} \mathrm{~S} / \mathrm{cm}$, with carrier mobility equals to $20 \mathrm{~V} / \mathrm{cm}^{2} \times \mathrm{s}$ and a high density of carriers which are almost equally positive and negative. These characteristics make the elaborated DLC film potentially suitable for developing new high performance conductive electrodes and optoelectronic sensors.

\section{Acknowledgements}

The authors would like to thank: T. Fix (Hall measurements), F. Stock (optical transmission analysis); N. Roques, D. Muller (NRA and RBS) at ICube/MaCEPV, Strasbourg; J. Faerber (SEM) and J. Arabski (MBE) at IPCMS, Strasbourg, are acknowledged for their contributions. Part of this research was supported by Exceptional National Program (178/P.N.E), funded by the Ministry of Higher Education and Scientific Research of Algeria, which is thanked for this fellowship.

\section{References}

[1] P. Avouris, C. Dimitrakopoulos, Graphene: synthesis and applications, Mater. Today 15 (2012) 86-97.

[2] A.H. Castro Neto, N.M.R. Peres, F. Guinea, K.S. Novoselov, A.K. Geim, The electronic properties of graphene, Rev. Mod. Phys. 81 (2009) 109-162.

[3] W.Y. Jang, Z. Chen, W.Z. Bao, Z.N. Lau, C. Dames, Thickness-dependent thermal conductivity of encased graphene and ultrathin graphite, Nano Lett. 10 (2010) 3909-3913.

[4] C.G. Lee, X.D. Wei, J.W. Kysar, J. Home, Measurement of the elastic properties and intrinsic strength of monolayer graphene, Science 321 (2008) 385-388.

[5] P. Blake, E.W. Hill, A.H. Castro Neto, K.S. Novoselov, D. Jiang, R. Yang, T.J. Booth, A.K. Geim, Making graphene visible, Appl. Phys. Lett. 91 (2007) (063124/1-3).

[6] A.C. Ferrari, F. Bonaccorso, V. Fal'ko, K.S. Novoselov, S. Roche, P. Bøggild, S. Borini, F.H.L. Koppens, V. Palermo, N. Pugno, J.A. Garrido, R. Sordan, A. Bianco, L. Ballerini, M. Prato, E. Lidorikis, J. Kivioja, C. Marinelli, T. Ryhänen, A. Morpurgo, J.N. Coleman, V. Nicolosi, L. Colombo, A. Fert, M. Garcia-Hernandez, A. Bachtold, G.F. Schneider, F. Guinea, C. Dekker, M. Barbone, Z. Sun, C. Galiotis, A.N. Grigorenko, G. Konstantatos, A. Kis, M. Katsnelson, S. Vandersypen, A. Loiseau, V. Morandi, D. Neumaier, E. Treossi, V. Pellegrini, M. Polini, A. Tredicucci, G.M. Williams, B.H. Hong, J.H. Ahn, J.M. Kim, H. Zirath, B.J. Van Wees, H. Van der Zant, L. Occhipinti, A. Di Matteo, I.A. Kinloch, T. Seyller, E. Quesnel, X.L. Feng, K. Teo, N. Rupesinghe, P. Hakonen, S.R.T. Neil, Q. Tannock, T. Löfwander, J. Kinaret, Science and technology roadmap for graphene, related todimensional crystals, and hybrid systems, Nanoscale 7 (2015) 4598-4810.

[7] A. Reina, X.T. Jia, J. Ho, D. Nezich, H.B. Son, V. Bulovic, M.S. Dresselhaus, J. Kong, Large area, few-layer graphene films on arbitrary substrates by chemical vapor deposition, Nano Lett. 9 (2009) 30-35.

[8] J. Robertson, Diamond-like amorphous carbon, Mater. Sci. Eng. R37 (2002) $129-281$.

[9] M.J. Fallon, V.S. Veerasamy, C.A. Davis, J. Robertson, G.A.J. Amaratunga,
W.I. Milne, J. Koskinen, Properties of filtered-ion-beam-deposited diamondlike carbon as a function of ion energy, Phys. Rev. B 48 (1993) 4777-4782.

[10] S. Rey, F. Antoni, B. Prevôt, E. Fogarassy, J.C. Arnault, J. Hommet, F. Le Normand, P. Boher, Thermal stability of amorphous carbon films deposited by pulsed laser ablation, Appl. Phys. A 71 (2000) 433-439.

[11] J.O. Orwa, I. Andrienko, J.L. Peng, S. Prawer, Y.B. Zhang, S.P. Lau, Thermallyinduced $\mathrm{sp}^{2}$ clustering in tetrahedral amorphous carbon (ta-C) films, J. Appl. Phys. 96 (2004) 6286-6297.

[12] M. Chhowalla, A.C. Ferrari, J. Robertson, G.A.J. Amaratunga, Evolution of sp2 bonding with deposition temperature in tetrahedral amorphous carbon studied by Raman spectroscopy, Appl. Phys. Lett. 76 (2000) 1419-1421.

[13] A.C. Ferrari, V. Stolojan, N.A. Morrison, A. Hart, B. Kleinsorge, J. Robertson, Stress reduction and bond stability during thermal annealing of tetrahedral amorphous carbon, J. Appl. Phys. 85 (1999) 7191-7197.

[14] J.P. Sullivan, T.A. Friedmann, A.G. Baca, Stress relaxation and thermal evolution of film properties in amorphous carbon, J. Electron. Mater. 26 (1997) 1021-1029.

[15] H.S. Jung, H.H. Park, S.S. Pang, S.Y. Lee, The investigation of thermal effect on the properties of pulsed laser deposited diamond-like carbon films, Thin Solid Films 332 (1998) 103-108.

[16] H. Dimigen, H. Hubsch, R. Memming, Tribological and electrical properties of metal-containing hydrogenated carbon films, Appl. Phys. Lett. 50 (1987) 1056-1058.

[17] J.P. Sullivan, T.A. Friedmann, R.G. Dunn, E.B. Stechel, P.A. Schultz, M.P. Siegal, N. Miessert, The Electronic Transport Mechanism in Amorphous TetrahedrallyCoordinated Carbon Films, Proceedings Materials Society Symposia, 498 1999, pp. 97-102.

[18] S. Tamulevičius, S. Meškinis, T. Tamulevičius, H.G. Rubahn, Diamond like carbon nanocomposites with embedded metallic nanoparticles, Rep. Prog. Phys. 81 (2018) (024501:1-31).

[19] K. Bewilogua, D. Hofmann, History of diamond-like films: from first experiments to worldwide applications, Surf. Coat. Technol. 242 (2014) 214-225.

[20] F. Stock, F. Antoni, F. Le Normand, D. Muller, M. Abdesselam, N. Boubiche, I. Komissarov, Diamond-like carbon layers obtained by pulsed laser deposition in different conditions for conductive electrodes application, Appl. Phys. A Mater. Sci. Process. 123 (2017) 590-595.

[21] N. Boubiche, F. Aweke, J. Hulik, W. Luo, M. Abdesslam, S. Zafeiratos, F. Djeffal F. Le Normand, Ultrathin DLC Films Coated with Transition Metals and its Transformation Into Graphitic Films by Thermal or Thermocatalytic Treatments, (2018) (in preparation).

[22] F.Z. Bouanis, I. Florea, M. Bouanis, A. Nyassi, D. Muller, F. Le Normand, D. Pribat, Diameter-controlled growth of SWCNTs using Ru as catalyst precursors coupled with hydrogen treatment, Chem. Eng. J. 332 (2017) 92-101.

[23] M.P. Siegal, D.R. Tallant, P.N. Provencio, R.L. Simpson, B. Kleinsorge, W.I. Milne, Bonding topologies in diamondlike amorphous carbon films, Appl. Phys. Lett. 76 (2000) 2047-2049.

[24] L. Changshi, L. Feng, Optical gap determination, Opt. Commun. 285 (2012) 2868-2873.

[25] S. Sinharoy, M.A. Smith, L.L. Levenson, The formation and decomposition of nickel carbide in evaporated nickel films on graphite, Thin Solid Films 53 (1978) 31-36.

[26] R. Kalish, Y. Lifshitz, K. Nugent, S. Prawer, Thermal stability and relaxation in diamond-like-carbon. A Raman study of films with different $\mathrm{sp}^{2} / \mathrm{sp}^{3}$ fractions (ta-C to a-C), Appl. Phys. Lett. 74 (1999) 2398-2936.

[27] A.C. Ferrari, J. Robertson, Interpretation of Raman spectra of disordered and amorphous carbon, Phys. Rev. B 61 (2000) 14095-14107.

[28] P.K. Chu, L.H. Li, Characterization of amorphous and nanocrystalline carbon films, Mater. Chem. Phys. 96 (2006) 253-277.

[29] N. Wada, S.A. Solin, Raman efficiency measurements of graphite, Physica B 105 (1981) 353-356.

[30] D.R. Mac Kenzie, D. Muller, B.A. Pailthorpe, Compressive-stress-induced formation of thin-film tetrahedral amorphous carbon, Phys. Rev. Lett. 67 (1991) 773-776.

[31] M.P. Siegal, D.R. Tallant, P.N. Provencio, D.L. Overmyer, R.L. Simpson, L.J. Martinez-Miranda, Ultrahard carbon nanocomposite films, Appl. Phys. Lett. 76 (2000) 3052-3054.

[32] M.P. Siegal, J.C. Barbour, D.R. Tallant, P.N. Provencio, T.A. Friedmann, Amorphous-tetrahedral diamondlike carbon layered structures resulting from film growth energetics, Appl. Phys. Lett. 73 (1998) 759-761.

[33] Y. Inoue, S. Nakashima, A. Mitsuishi, Raman spectra of amorphous SiC, Solid State Commun. 48 (1983) 1071-1075.

[34] C.A. Klein, W.D. Straub, Carrier densities and mobilities in pyrolytic graphite, Phys. Rev. 123 (1961) 1581-1583.

[35] Z.H. Zhai, H.L. Shen, J.Y. Chen, X.M. Li, Y. Jiang, Evolution of structural and electrical properties of carbon films from amorphous carbon to nanocrystalline graphene on quartz glass by HFCVD, ACS Appl. Mater. Interfaces 10 (2018) $17427-17436$.

[36] A. Ilie, Electronic transport, photoconductivity and photoluminescence in amorphous carbon, Diam. Relat. Mater. 10 (2001) 207-215.

[37] A. Ilie, A.C. Ferrari, T. Yagi, S.E. Rodil, J. Robertson, E. Barborini, P. Milani, Role of $\mathrm{sp}^{2}$ phase in field emission from nanostructured carbons, J. Appl. Phys. 90 (2001) 2024-2032.

[38] D. Dasgupta, F. Demichelis, A. Tagliaferro, Electrical conductivity of amorphous carbon and hydrogenated amorphous carbon, Philos. Mag. B 63 (1991) 1255-1266.

[39] J. Robertson, E.P. O'Reilly, Electronic and atomic structure of amorphous carbon, Phys. Rev. B 35 (1987) 2946-2957.

[40] Y. Lifshitz, S.T. Lee, X.M. Meng, R. Akhveldiany, A. Hoffman, Visualization of diamond nucleation and growth from energetic species, Phys. Rev. Lett. 93 (2004) 056101. 